\title{
Quality evaluation of Coconut Based Snack during storage period
}

\author{
M. Sivasakthi ${ }^{1}$, Narayanasamy Sangeetha ${ }^{2}$ \\ ${ }^{1}$ Department of Nutrition and Dietetics, Dr.N.G.P. Arts and Science College, Coimbatore-641 048, India \\ ${ }^{2}$ Department of Food Science and Technology, Pondicherry University, Pudhucherye-605014, India
}

Available online at: www.isroset.org

Received: 02/Jan/2019, Accepted: 10/Feb/2019, Online: 30/Jun/2019

\begin{abstract}
Natural versatile ingredients packed with potent nutrients such as beet root, carrot, ginger and mint have been selected for the recent study for their variable vast phenolic compounds and other functional properties as osmotic infusions in the form of filtrates. Sliced samples $(0.8 \pm 0.1 \mathrm{~mm})$ of matured coconuts were subjected to the process osmotic dehydration from $0 \mathrm{~min}$ to $720 \mathrm{~min}$ at room temperature. Then the slices were dried in a hot-air oven at temperature $45-60^{\circ} \mathrm{C}$ for about 6-7 hours and freeze drying at temperature $\left(-40\right.$ to $\left.30^{\circ} \mathrm{C}\right)$ for a period of $14-16$ hours. Osmotic medium without the infusion of filtrates of functional ingredients serves as the control. The snack samples were packed using Aluminium foil laminated LDPE pouches with infusion of $100 \%$ nitrogen gas composition and stored at ambient temperature till analyzing the shelf life features like free fatty acids, peroxide value, total sugars, moisture content and microbial growth and the results were interpreted using SPSS tool t test $(p \leq 0.05)$. Upon three months of storage study, the products quality remained good, where as slight deterioration of shelf life characteristics seen beyond three months, showed the keeping quality of the snack.
\end{abstract}

Keywords: Osmotic dehydration, coconuts, shelf life properties, impregnation, antioxidants

\section{INTRODUCTION}

Coconut is a versatile product and has multiple uses. It possess excellent antioxidant and anti-inflammatory properties, since it holds medium chain fatty acids, proteins, vitamins and minerals. People consume well grown fresh coconut every day in food preparations and being used in pharmaceutical findings with respect to various ailmens. India is one of the principal coconut producers in the world, producing 13 billion nuts per annum. Coconut is typically cultivated in the coastal regions of the nation. The states that have plentiful coconut production are Andhra Pradesh, Assam, Goa, Karnataka, Kerala, Maharashtra, Orissa, Tamil Nadu, Tripura, West Bengal, Andaman and Nicobar Islands, Lakshadweep and Pondicherry (1).

Coconut is an admired plantation and is full-grown in more than 90 countries at global outlook. Though it is rather difficult to begin a coconut plantation but once it is made, it proves to be beneficial as coconut is harvested all round the year. The global production of coconut sums around 55 million tonnes per annum. Indonesia and Philippines are the major coconut producers in the world.Currently, India holds the third place in the list of major coconut producing countries of the world. Kerala, the largest producer of coconuts in India, accounts for around 45 per cent of the country's total production. A variety of value added coconut products are manufactured in the nationwide which have both domestic and commercial applications. The preservation and packaging technologies plays a well-known role in seasonal export of coconut products all over the country (1).

Functional foods represents foods rich in antioxidants, phytochemicals which protects body from life threatenind diseases. Generally roots, vegetables and fruits chiefly rich in bioactive constituents in a plant based diet relatively possess therapeutic properties help to withstand better mental and physical health (2).

Osmotic dehydration is a primary treatment given to plant foods used to progress the organoleptic, nutritional, and functional qualities of food without changing its reality $(2,3)$. It partially dehydrates solid foods and instantaneously infuses it with solutes that modify its functional, nutritional and structural properties $(4,5)$. Apart from using various osmotic agents such as sodium chloride, fructose, corn syrup, glucose, sucrose and other combinations, the incorporation of plant based filtrates paying attention in recent researches as osmotic medium for effective therapeutic significance.

The present study highlights the importance on osmotic dehydration of coconut slices with the impregnation of filtrates of functional ingredients such as Daucus carota, Beta vulgaris, Mentha piperita and Zingiber officinale which have immense nutritional and antioxidant qualities subjected to osmotic dehydration followed by implementation of drying methods such 
using hot air oven and freeze drying. The current study focused on developing value added coconut based snack with enriched nutritional profile and extended shelf life. With this view, the objectives were framed to analyse the free fatty acids, peroxide value, sugars, moisture and microbial content.

\section{RELATED WORK}

The present study was in par with the existing study done by Torreggiani (3) and Alzomora et al., (4) osmotic dehydration with impregnation of sugar and salt solution and also functional infusions in plant tissues.

\section{MATERIALS AND METHODS}

\section{Selection and primary processing of raw materials}

Coconuts (matured) were purchased from Pazhamudir Nilayam of Puducherry owing to set of treatments prior to osmotic dehydration. The pre-processing of coconut usually involves selection of coconut (10-12 months), husk removal, breaking into halves, endosperm removal from shell and removal of testa (brown skin) from endosperm using a sharp knife. The preprocessed coconut slices were standardised to get hold of optimum thickness of slices using slicers and screw gauge.

The efficacy of osmotic process depends on the thickness of the food slices like vegetables and fruits. Torreggiani (3) investigated that the rate of dehydration due to osmotic process decreases as the thickness of the slices increases which results in less penetration of the solute to the foods. The coconut slices of thickness $0.5,0.6,0.7,0.8,0.9$ and $1.0 \mathrm{~mm}$ thickness were selected for standardization. Nevertheless, coconut slice of thickness $0.8 \mathrm{~mm}$ have been selected as optimized one based on crispiness and other textural features determined after several trials.

The sliced coconut slices were kept in water before beginning of experiments to avoid microbial attack. The sliced coconut slices were directed to steam blanching at temperature 80 to $90^{\circ} \mathrm{C}$ for 3-5 minutes to cease enzymatic destructions. Further, the pre-processed coconuts were osmo- dehydrated using sugar, since it is economical and cost-effective with greater rate of diffusion and own superior mass transfer properties as studied by Nicoletti et al., (6).

The filtrates from functional ingredients were obtained namely Daucus carota, Beta vulgaris, Daucus carota, Mentha piperita, Zingiber officinale and Mentha piperita, purchased from Pazhamudir Nilayam, Puducherry. The processing steps like clean washing, peeling, grating, grinding of functional ingredients were carried out to get fine paste and finally filtered to obtain filtrates using $0.08 \mathrm{~mm}$ sieve.

The filtrates were taken in the range from every $5 \%$ up to $100 \%$ and infused with sugar solution as the osmotic medium $(100 \%)$. The thickness of coconut slices, sugar concentration and concentration of filtrates were taken in three ratios such as $1: 1: 1,1: 2: 2$ and $1: 3: 3$ for standardization purpose.

\section{Process involved in the development of the coconut based snack}

The coconut slices were osmo- dehydrated with or without the infusion of filtrates of functional ingredients for a period from 0 $\min$ to $720 \mathrm{~min}$. The duration of the osmotic process was finalised based on the physical characteristics and physico-chemical of the samples. Dehydration is a preservation method of food preservation phenomenon which involves effective moisture loss, results in ruin of micro-organisms and leads to greater shelf-life. It results in effectual decline in volume and mass, minimise packaging, charges, storage space and transportation costs and makes storage under ambient condition conveniently. Hot air drying and freeze-drying methods were used in the present study for supplementary dehydration.

The coconut slices were dehydrated in hot air oven, the desirable moisture content was achieved due to moisture deduction up to $2-3 \%$. The desired moisture content was optimised at standardised temperature $45-50^{\circ} \mathrm{C}$ for a duration of $6-7$ hours which was dependent mostly on the nature of the food product. Whereas most of the vegetables and fruits are dehydrated at temperature $50-60^{\circ} \mathrm{C}$ to obtain dried foods without much deteriorative reactions (14). The coconut slices were dried using freeze dryer (Model: Del Vac) by spreading the samples uniformly in the trays, ensured that the instrument works under vacuum condition $\left(-30\right.$ to $\left.40^{\circ} \mathrm{C}\right)$.

The dehydrated coconut slices from both the drying methods were packed in Aluminium Foil Laminated LDPE pouches with the impregnation of $100 \%$ nitrogen gas (MAP technology) and stored at room temperature $\left(35^{\circ} \mathrm{C}\right)$ for further analysis. Standardised process parameters.

After several permutations and combinations, the process parameters were standardised from the above methods and obtained in the ratio 1:2:2. The thickness of coconut slices, concentration of sugar and concentration of filtrates from the functional ingredients were standardized and above ratio is followed for further processing steps. The sugar and infusion of filtrates of 
functional ingredients at $100 \%$ concentration contributed the coconut based snack with maximum acceptability traits such as texture, taste, crispiness and sweetness; hence this proportion was selected finally. Whereas the osmotic dehydration of the coconut slices without the infusion of filtrates of functional ingredients serves as the control.

\section{Quality evaluation of the coconut based snack}

After the standardisation of process parameters, various quality attributes of the coconut based snack have been analyzed for shelf-life properties as per standard protocols. All analytical determinations were performed in triplicates. Values were expressed as mean \pm standard deviation.

\section{Shelf- life characteristics of the ready to eat coconut based snack}

The food deterioration occurs mainly due to oxidative rancidity and the acceptability of a food product is assessed by degree of deterioration. The food safety depends on the extent of oxidative reactions happened over prolonged storage period (7). The sensory characteristics like color, texture, taste, flavour and overall acceptability of the snack food was analysed with respect to the extent of oxidative products formation such as Aldehydes, ketones and peroxides during storage period. The common chemical tests such as free fatty acids, Saponification value, Peroxide value and Total microbial load have been employed to assess the quality traits of the coconut based snack during storage period.

\section{Oxidative products formation}

Free fatty acid (\%) content

The free fatty acids content of the oil was determined volumetrically using aqueous sodium hydroxide $(0.1 \mathrm{M})$ and phenolphthalein indicator (1\% ethanol) according to AOAC (8) method. A neutral mixture of diethyl ether: ethanol (1:1) (50 $\mathrm{ml}$ ) was used as a solvent. FFA values were reported as \% oleic acid by weight.

\section{Peroxide (meq/kg of oil) value}

The peroxide value was determined and expressed as meq $\mathrm{O}_{2} / \mathrm{kg}$ oil, according to AOAC (8) method. Oil samples were dissolved in chloroform and mixed with glacial acetic acid (Sigma) and freshly prepared saturated potassium iodide solution. Liberated iodine was titrated with standard sodium thiosulphate $(0.01 \mathrm{M})$ solution using starch indicator $(1 \%)$.

\section{Saponification (mg KOH/g) value}

Saponification value was determined according to AOAC (8) Cd 3-25 method. It is the number of KOH required to saponify 1 gram of oil. Saponification is the hydrolysis of ester under alkaline condition.

\section{Sensory analysis}

Sensory evaluation is defined as specific discipline used to evoke, measure, analyze and interpret the characteristics of food and materials as they are perceived by the senses of sight, smell, taste, touch, and hearing. The primary function of sensory testing is conducted valid and reliable tests to provide data on which sound decision may be made (9).

\section{Selection of the panel member}

Fifteen research scholars of the Department of Food Science and Technology were requested to take up threshold sensitivity test using salt, sweet, sour and bitter (9). They were mixed in the different composition with the code numbers and the subjects were asked to identify the sequence of the concentration from low to high. Essentially the threshold test determines the sensitivity of the panellist to a particular test.

\section{Formulation of score card for sensory evaluation}

A score card is a visual exhibit of the most significant information needed to accomplish oneor more objectives, combined and arranged on a single screen so the information could be observed at a glance. The score card is prepared suspiciously and it is clearly printed (10).

\section{Storage and keeping quality}

Storage plays an important role in the safety and the quality of the product. Thirty gram of the snack was packed in Aluminium Foil Laminated LDPE pouches with composition of $100 \%$ nitrogen gas and stored in ambient temperatures. Care was taken to see that the snack was stored in clean and dry place which was away from sunlight and pests. Sensory evaluation of the snack was done once in 15 days and microbial testing once in 30 days over a period of 90 days to analyse the extent of storage. 


\section{Preparation of sample for microbial analysis}

Specific agar medium was prepared and poured in the petri plates and kept aside for setting. One gram of the sample was weighed in aseptic condition and mixed in $10 \mathrm{ml}$ of saline solution. Then the mixture is streaked in the agar medium and incubated. After 48 hours the number of colonies was counted.

\section{Evaluation of the product}

Sensory evaluation of hot air oven and freeze dried coconut based snacks prepared under different treatments was carried by a panel of fifteen judges. The various products (Sample A, Sample B, Sample C and Sample D were displayed on a desk and random numbers were consigned to the judges. The judges were asked to examine the samples carefully for appearance, flavor, and taste and color using the 9-Point Hedonic scale. Here, different ratings, ranging from "Like extremely" to "dislike extremely" were given by the judges, specifying the values from 9 (like extremely) to 1 (dislike extremely), respectively. Later on, the scores were averaged for each treatment. Treatments which gained a mean score of 5 and above are acceptable and the one's which score below 5 points were rejected. This experiment was conducted under a controlled environment in cool place. The results of the sensory analysis led way to select the most acceptable products prior to further analysis (9).

\section{Statistical interpretation of the data}

The analyses on sensory, physical, chemical, functional, phytochemical and shelf-life characteristics were done using triplicate samples. The data on experimental results were subjected to Analysis of Variance (ANOVA) and differences between means were assessed by LSD and independent sample ' $t$ ' test using the statistical package SPSS (18 version) to compare the means to determine the most acceptable treatment $(p \leq 0.05)$.

\section{RESULTS AND DISCUSSION}

\section{Effect of drying methods and impregnation of filtrate of functional ingredients on Shelf- life characteristics of the ready to eat coconut based snack}

The food deterioration occurs mainly due to oxidative rancidity and the acceptability of a food product is assessed by degree of deterioration. The food safety depends on the extent of oxidative reactions happened over prolonged storage period (2). The sensory characteristics like color, texture, taste, flavour and overall acceptability of the snack food was analysed with respect to the extent of oxidative products formation such as Aldehydes, ketones and peroxides during storage period. The common chemical tests such as free fatty acids, Saponification value, Peroxide value and Total microbial load have been employed to assess the quality traits of the coconut based snack during storage period.

In the present study, the coconut based snacks developed with the impregnation of filtrates of functional ingredients coded Sample A (Mentha piperita), Sample B (Zingiber officinale), Sample C (Daucus carota), Sample D (Beta vulgaris) and Control snack developed without the impregnation of filtrates of functional ingredients were subjected to two different drying methods namely hot-air oven drying $\left(\mathrm{T}_{1}\right)$ and freeze-drying $\left(\mathrm{T}_{2}\right)$ and the results pertaining to shelf-life study of the product are discussed and interpreted.

\section{Microbiological analysis of the ready-to-eat coconut based snack during storage}

The Table 1 explains the microbiological analysis of the ready-to-eat coconut based snack. The total microbial counts (cfu/grams) of osmotic treated $T_{1}$ as well as $T_{2}$ samples were shown with slight progress in microbial growth but was found safe during 3 months of storage periods with good sensory acceptability scores as suggested by panelists. As the ready to eat coconut based snack was impregnated with functional filtrate and sugar $\left(52^{\circ} \mathrm{Bx}\right)$ which serves as a preservative and packed in aluminium foil laminated LDPE pouches of thickness $0.08 \mathrm{~mm}$ with the application of nitrogen gas under MAP technology limited the permeability of air to curtail the growth of microorganism. Generally the osmotic dehydrated products packed under MAP had a better preservation of color with good microbial conditions and the organisms which are responsible for contamination are destroyed on blanching, the temperatures are found fatal to the growth of moulds and yeasts. In the present study, blanching was carried out at the beginning of osmotic dehydration process either with or without the functional infusions.

Table 1. Microbiological analysis $(\mathrm{CFU} / \mathrm{g})$ of the ready-to-eat coconut based snack $\left(\mathrm{T}_{1} \& \mathrm{~T}_{2}\right)$ during storage

\begin{tabular}{|c|c|c|c|}
\hline Samples & Storage period & $T_{1}$ samples cfu /gram & $T_{2}$ samples cfu /gram \\
\hline A & \multirow{3}{*}{0 month } & $2 \times 10^{2}$ & $1.2 \times 10^{2}$ \\
\hline B & & $2.4 \times 10^{2}$ & $1.4 \times 10^{2}$ \\
\hline $\mathrm{D}$ & & $3.1 \times 10^{2}$ & $1.5 \times 10^{2}$ \\
\hline
\end{tabular}




\begin{tabular}{|c|c|c|c|}
\hline Control & & $3.5 \times 10^{3}$ & $2.4 \times 10^{3}$ \\
\hline A & \multirow{5}{*}{$1^{\text {st }}$ month } & $1.2 \times 10^{5}$ & $2.1 \times 10^{5}$ \\
\hline B & & $2.1 \times 10^{4}$ & $1.2 \times 10^{4}$ \\
\hline $\mathrm{C}$ & & $1.6 \times 10^{5}$ & $1.3 \times 10^{5}$ \\
\hline $\mathrm{D}$ & & $3.2 \times 10^{5}$ & $2.6 \times 10^{5}$ \\
\hline Control & & $2.5 \times 10^{6}$ & $2.2 \times 10^{6}$ \\
\hline A & \multirow{4}{*}{$2^{\text {nd }}$ month } & $1.4 \times 10^{6}$ & $2.2 \times 10^{6}$ \\
\hline $\mathrm{C}$ & & $3.1 \times 10^{6}$ & $2.3 \times 10^{6}$ \\
\hline $\mathrm{D}$ & & $2.3 \times 10^{6}$ & $3.1 \times 10^{6}$ \\
\hline Control & & $2.5 \times 10^{7}$ & $1.6 \times 10^{7}$ \\
\hline A & \multirow{2}{*}{$3^{\text {rd }}$ month } & $1.4 \times 10^{7}$ & $1.2 \times 10^{7}$ \\
\hline B & & $1.2 \times 10^{7}$ & $1.6 \times 10^{7}$ \\
\hline
\end{tabular}

Moisture (\%) content of the ready-to-eat coconut based snack during storage

Figures 1 and 2 give the moisture content of the ready-to-eat coconut based snack during storage. Hot air drying helps to produce dehydrated foods of lowest moisture content with restricted microbial growth that result in decay and decreases moisture-related deteriorative changes. It ensures significant reduction in mass and volume, reducing packaging, storage and transportation costs and entails storage of the product under ambient temperatures. On observing the moisture content of the samples over three months of storage period, a slight significant increase $(p \leq 0.05)$ in moisture content was noted around 2 to 7\%. The samples packed in Aluminium Foil Laminated LDPE pouches of thickness $0.08 \mathrm{~mm}$ with the application of nitrogen gas under MAP technology limited the permeability of air and thereby reducing the moisture content of impregnated samples subjected to $\mathrm{T}_{1}$ and $\mathrm{T}_{2}$.

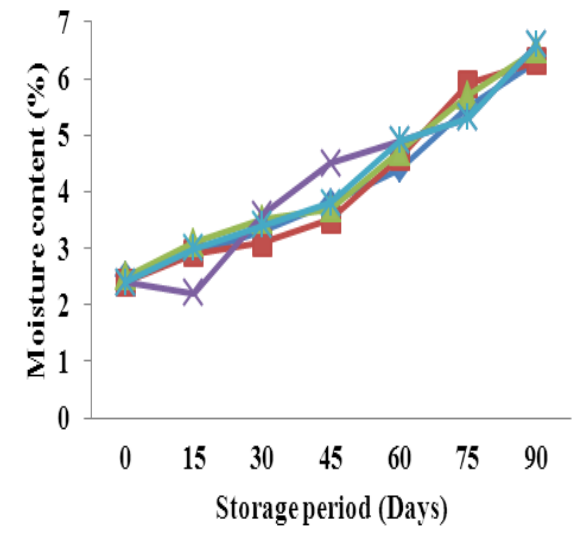

Figure 1. Moisture content (\%) of the ready-to-eat coconut based snack $\left(T_{1}\right)$ during storage

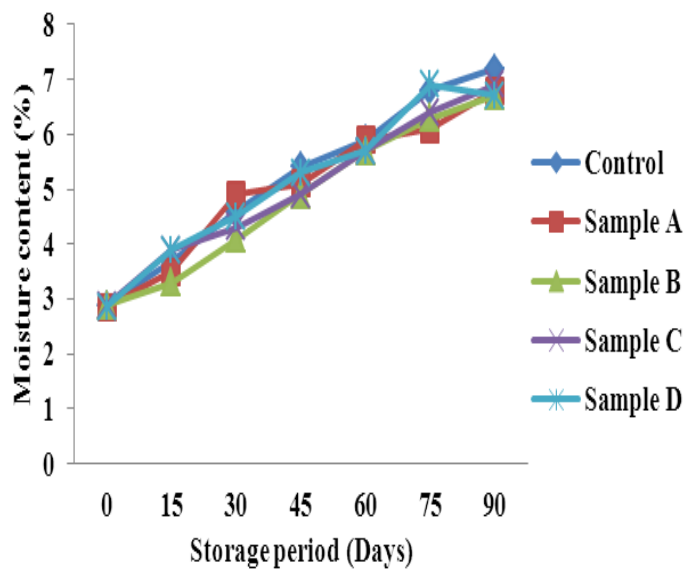

Figure 2. Moisture content $(\%)$ of the ready-to-eat coconut based snack $\left(T_{2}\right)$ during storage

\section{Total sugar (g) content of the ready-to-eat coconut based snack during storage period}

The Total sugar content of the ready-to-eat coconut based snack during storage is discussed in Figures 3 and 4 . The mean total sugar content of the control and the impregnated samples subjected to $\mathrm{T}_{1}$ and $\mathrm{T}_{2}$ were found decreased from 23.33 to 22.74 initially and 25.01 to 24.35 finally. Similarly in case of impregnated samples, the range was 30.83 to 26.43 observed initially and 30.16 to 25.54 was observed finally after the storage period of 3 months and showed a significant difference $(p \leq 0.05)$. The decrease in the total sugar content is mainly due to the inter conversion of sugars, aggregation of monomers and macromolecule hydrolysis reactions. 
The finding was similar to the result of Rahman and Lamb (11) who was observed that total sugar content of osmotic dehydrated jackfruit found to decrease when there is an increase in reducing sugar content during 8 months storage period. The subsequent decline in total sugar values could be due to the increment in reducing sugars significantly in osmotic treated jackfruit by the process of acid hydrolysis happened in both reducing and total sugars.

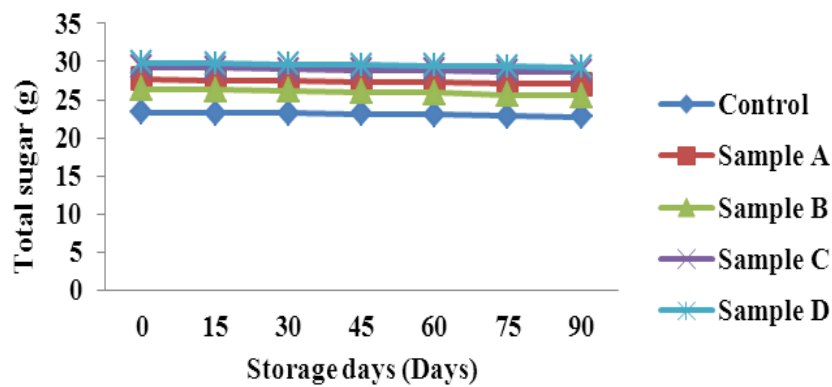

Figure 3. Total sugar $(\mathrm{g})$ content of the readyto-eat coconut based snack $\left(T_{1}\right)$ during storage

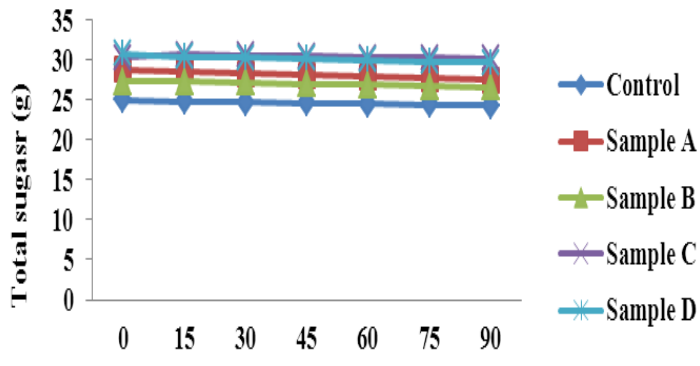

Figure 4. Total sugar (g) content of the readyto-eat coconut based snack $(T$,) during storage

\section{$B$-carotene $(\mu \mathrm{g})$ content of the ready-to-eat coconut based snack during storage}

Figures 5 and 6 shows the $\beta$-carotene content of the ready-to-eat coconut based snack during storage. Among root vegetables, carrots consists about $50 \%$ of dietary beta carotene and $90 \%$ of dietary alpha-carotene whilst other root vegetables such as beet root, rutabaga, turnip, radish and celeriac consisted carotenoids in poor amount.

The $\beta$-carotene content of the samples subjected to the hot air oven drying and freeze drying showed a decrease in the levels over the period of three months. It is observed that carotenoids are naturally unstable pigments and due to its unsaturated molecular structure, the pigments might undergo isomerisation reactions which could result in loss of color and oxidation process.The result of the present study was in par with the outcome of Ranganna (12) where decrease in vitamin A from $2.66 \%-4.79 \%$ in dehydrated okra samples on storage period was observed. Also he pointed out that most of the physico chemical characteristics of oven dried okra remained good on air-tight storage containers in the absence of light.

According to Harnkarnsujarit and Charoenrein (13) reported that beta carotene values of freeze-dried mangoes declined around 57\%, 43\%, and 59\% when analysed under different protocols. Similarly Negi and Roy (14) observed the beta carotene content in dehydrated (cabinet and solar dried) beet and amaranth leaves which revealed that there was a firm loss in products during increased storage period.

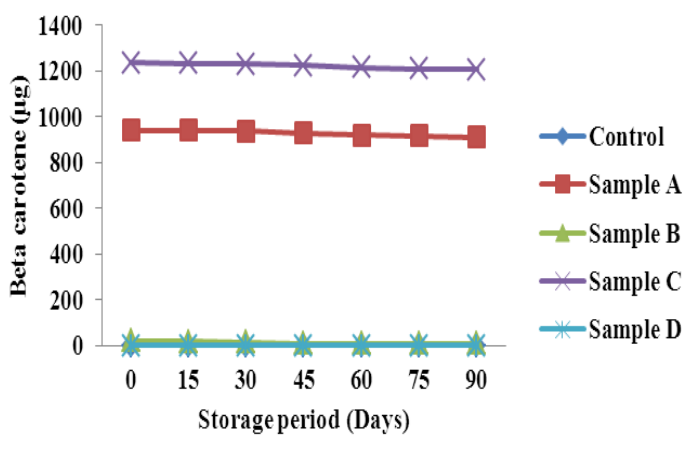

Figure 5. B-carotene $(\mu \mathrm{g})$ content of the ready-to-eat coconut based snack $\left(T_{1}\right)$ during storage

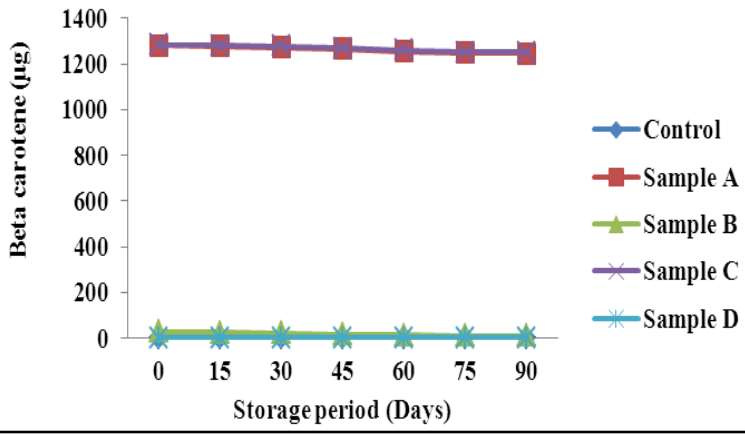

Figure 6. B-carotene $(\mu \mathrm{g})$ content of the ready-to-eat coconut based snack $\left(T_{2}\right)$ during storage

Table 2 explains the ascorbic acid content of the ready-to-eat coconut based snack during storage period. Similarly ascorbic acid content of control and impregnated samples subjected to $T_{1}$ and $T_{2}$ showed slightly greater values at initial stage of storage period due to the effect of osmotic process and drying which diminished during storage periods of months. The decline $(p \leq 0.05)$ in $\beta$-carotene and ascorbic acid content during 3 months storage period might be due to the existence of air and light which could lead to decline in vitamin content by oxidative reactions (15).

Table 2. Ascorbic acid $(\mathrm{mg})$ content of the ready-to-eat coconut based snack $\left(T_{1} \& T_{2}\right)$ during storage 


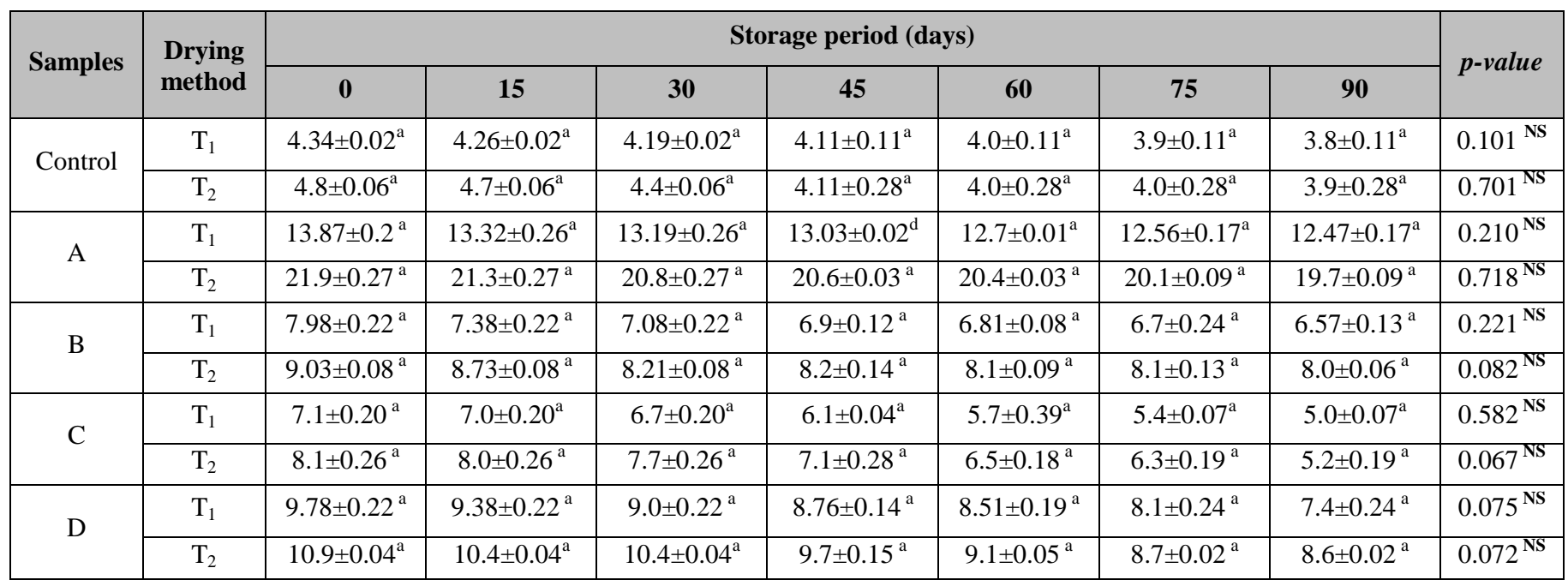

All values are means of triplicate determinations \pm standard deviation (SD), $\mathrm{T}_{1}$ - Hot Air Oven Drying, $\mathrm{T}_{2}$ - Freeze Drying Sample A-Mentha piperita, Sample B-Zingiber officinale, Sample C-Daucus carota and Sample D-Beta vulgaris filtrate impregnated coconut based snack, Rows followed by different alphabets are *Significantly different ( $\mathrm{p} \leq 0.05)$, NS- Not Significant by LSD.

The results of the present study were in agreement with the finding of Lee and Kader (16) who stated that loss of vitamin content inacerola was observed during drying methods at high and low temperatures. Whereas the loss in freeze dried acerola samples was comparatively smaller than samples dried by other methods.

Though the ascorbic acid content of the samples remained higher at initial stage of storage period, but subsequent storage caused reduction in values. In the present study, the aluminium foil laminated LDPE packages were used, which preserved the quality of the coconut based snack to some extent within the acceptable standard upper limits.

The decrease in ascorbic acid content in the current research was slightly higher in hot air dried samples than freeze dried samples without any significant difference $(\mathrm{p} \geq 0.05)$ could be due to the period of adaptation to attain chemical equilibrium of constituents as a result of ascorbate oxidase as supported by Chang et al., (17). The minimal reduction of ascorbic acid levels noted in the present study might be due to the preservative action of sugar, which was used as an osmotic agent.

\section{Oxidative products formation}

Generally the peroxide value (PV), free fatty acids (FFA) and saponifcation value (SV) represents the oxidative products formation over 3 months of storage.

\section{Free fatty acids (\%) content of the ready-to-eat coconut based snack during storage}

The free fatty acids content of the ready-to-eat coconut based snack were assessed and revealed favourable results during storage. The average mean of FFA (\%) of the samples subjected to $\mathrm{T}_{1}$ and $\mathrm{T}_{2}$ were found to increase from 0.31 to 0.32 and 0.3 to 0.31 . The FFA content exists during the breakdown of hydroperoxides into ketones and aldehydes. The free fatty acids contents of the sample analyzed were well within the critical value of $0.5 \%$ as recommended by APCC standard. The increase in FFA observed in the product during storage might be due to oxidative rancidity was consistent with the outcome of Choe and Min (18) who reported that FFA content increased linearly was similar to moisture content during storage period.

Koczon et al., (19) reported that market value of any product depends on the extent of deteriorative reaction of fat oxidation. In the current research the development of FFA during storage period resulted on formation of hydroperoxides which where the initial accumulates of oxidation followed by breakdown of those constituents resulting in the formation of lower-molecular weight components like alcohols, ketones, aldehydes and free fatty acids which ultimately lead to autoxidative rancidity. Generally the above reactions are hastened by light and oxygen exposure.

\section{Peroxide value (meq/kg of oil) content of the ready-to-eat coconut based snack during storage}

Figures 7 and 8 illustrate the peroxide value of the ready-to-eat coconut based snack during storage. The average mean PV of osmotic treated $\mathrm{T}_{1}$ as well as $\mathrm{T}_{2}$ sample were found to increase from 1.06 to 1.52 and 1.31 to 1.421 respectively which was not statistically significant $(p \geq 0.05)$. The meager increase in the peroxide values is due to the production of hydro peroxides at slower rates. But the PV of all the samples was within the standard upper limits $(10 \mathrm{meq} / \mathrm{kg})$ as recommended by Bureau of 
Indian Standards (BIS). The increment in peroxide value of the snacks over 3 months of storage period was similar to the finding of Abascal et al., (20) who stated that peroxide values are the indicators of lipid oxidation, which measures the hydroperoxides content in foods. The storage study on deep fried rice broken snacks revealed gradual increase in PV which was correlated linearly with all the samples. The PV of the snacks being increased significantly from 0.5 to $2.35 \mathrm{meq} / \mathrm{kg}$ on 30 days storage period.

The peroxide formation occurred in the coconut based snacks developed under $\mathrm{T}_{1}$ and $\mathrm{T}_{2}$ techniques during storage period. The peroxides are formed when unsaturated fatty acids react with oxygen accompanied by chain reactions having rancid flavor. Whereas such peroxide formation in $\mathrm{T}_{2}$ snacks could be due to the hygroscopic nature of the snacks enabled easy moisture absorption, which was similar to the result of

Abascal et al., (20) who conducted a study on freeze dried medicated capsules and found that there is a possibility of getting degradation faster when the products exposed to oxygen and also the shelf-life gets affected once the packaging opened to air. Harnkarnsujarit and Charoenrein (13) reported that the porous structure of the freeze-dried products possess lowest oxidative stability because it results in contact with oxygen due to increased contact area. Also he stated that there are more chances of oxidative reactions in freeze dried products due to enlarged pore structures.

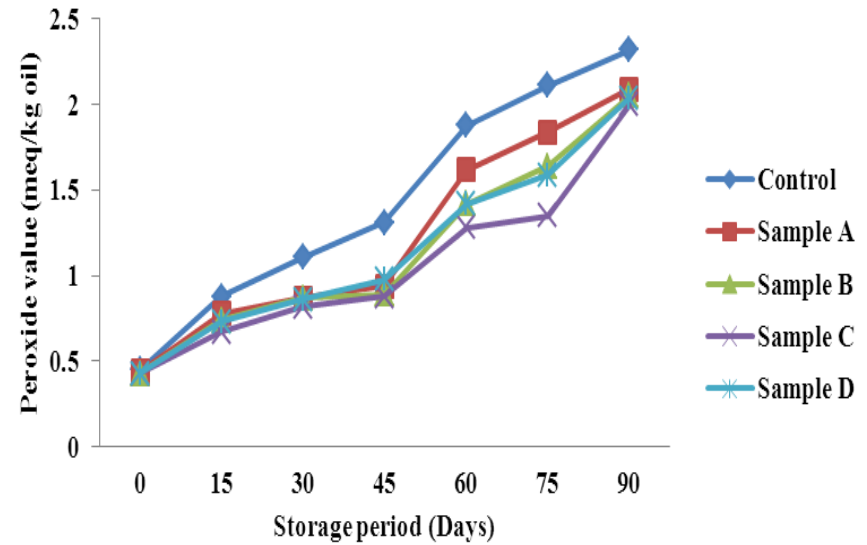

Figure 7. Peroxide value (meq/kg of oil) of the ready-toeat coconut based snack $\left(T_{1}\right)$ during storage

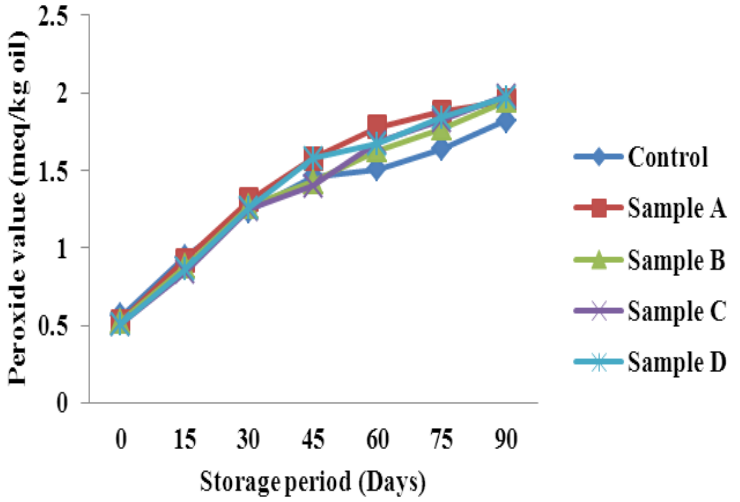

Figure 8. Peroxide value (meq/kg of oil) of the ready-to-eat coconut based snack $\left(\mathrm{T}_{2}\right)$ during storage

\section{Saponification value ( $\mathrm{mg} \mathrm{KOH} / \mathrm{g}$ ) content of the ready-to-eat coconut based snack during storage}

Table 3 depicts the saponification value of the ready-to-eat coconut based snack during storage

The average mean saponifcation value of the samples subjected to $\mathrm{T}_{1}$ and $\mathrm{T}_{2}$ ranged from 15 to 24.857 and 17.71 to 28.42 respectively. The increase in SV was observed during the oxidative end product formations especially in the case of hydrolysis reactions on FFA. The result of the present study was made in agreement with Boran et al., (21) who reported that the end products free fatty acids or aldehydes and ketones are formed during hydrolysis and lipid oxidation. The increase in SV was observed during the oxidative end product formations.

Table 3. Saponification ( $\mathrm{mg} \mathrm{KOH/g)} \mathrm{value} \mathrm{of} \mathrm{the} \mathrm{ready-to-eat} \mathrm{coconut} \mathrm{based} \mathrm{snack}\left(\mathrm{T}_{1} \& \mathrm{~T}_{2}\right)$ during storage

\begin{tabular}{|c|c|c|c|c|c|c|c|c|c|}
\hline \multirow{2}{*}{ Samples } & \multirow{2}{*}{ Drying method } & \multicolumn{7}{|c|}{ Storage period (days) } & \multirow[b]{2}{*}{ p-value } \\
\hline & & $\mathbf{0}$ & 15 & 30 & 45 & 60 & 75 & 90 & \\
\hline \multirow{2}{*}{ Control } & $\mathrm{T}_{1}$ & $11.3 \pm 0.42^{\mathrm{a}}$ & $14.0 \pm 0.09^{b}$ & $16 \pm 0.080^{c}$ & $18 \pm 0.160^{\mathrm{d}}$ & $19 \pm 0.210^{\mathrm{e}}$ & $21 \pm 0.070^{f}$ & $22 \pm 0.30^{\mathrm{g}}$ & $0.001 *$ \\
\hline & $\mathrm{T}_{2}$ & $13.3 \pm 0.44^{\mathrm{a}}$ & $16.0 \pm 0.13^{b}$ & $19 \pm 0.220^{c}$ & $22 \pm 0.220^{\mathrm{d}}$ & $23 \pm 0.20^{\mathrm{e}}$ & $24 \pm 0.330^{f}$ & $26 \pm 0.180^{g}$ & $0.002 *$ \\
\hline \multirow{2}{*}{ A } & $\mathrm{T}_{1}$ & $9 \pm 0.24^{\mathrm{a}}$ & $12 \pm 0.18^{b}$ & $14 \pm 0.190^{c}$ & $16 \pm 0.180^{\mathrm{d}}$ & $17 \pm 0.030^{\mathrm{e}}$ & $18 \pm 0.210^{f}$ & $19 \pm 0.310^{\mathrm{g}}$ & $0.003^{*}$ \\
\hline & $\mathrm{T}_{2}$ & $10 \pm 0.42^{\mathrm{a}}$ & $13 \pm 0.17^{b}$ & $16 \pm 0.180^{c}$ & $19 \pm 0.310^{\mathrm{d}}$ & $21 \pm 0.10^{\mathrm{e}}$ & $22 \pm 0.220^{f}$ & $23 \pm 0.20^{\mathrm{g}}$ & $0.004 *$ \\
\hline \multirow[b]{2}{*}{ D } & $\mathrm{T}_{1}$ & $19 \pm 0.310^{\mathrm{a}}$ & $22 \pm 0.30^{b}$ & $24 \pm 0.330^{c}$ & $26 \pm 0.180^{d}$ & $27 \pm 0.230^{\mathrm{e}}$ & $28 \pm 0.320^{f}$ & $29 \pm 0.20^{\mathrm{g}}$ & $0.001 *$ \\
\hline & $\mathrm{T}_{2}$ & $20 \pm 0.170^{\mathrm{a}}$ & $23 \pm 0.40^{b}$ & $26 \pm 0.180^{c}$ & $29 \pm 0.20^{d}$ & $30 \pm 0.350^{\mathrm{e}}$ & $31 \pm 0.150^{f}$ & $32.05 \pm 0.1^{\mathrm{g}}$ & $0.004 *$ \\
\hline
\end{tabular}




\begin{tabular}{|c|c|c|c|c|c|c|c|c|c|}
\hline \multirow{2}{*}{$\mathrm{C}$} & $\mathrm{T}_{1}$ & $19 \pm 0.23^{a}$ & $22 \pm 0.22^{b}$ & $24 \pm 0.330^{c}$ & $26 \pm 0.180^{d}$ & $26 \pm 0.180^{d}$ & $28 \pm 0.320^{f}$ & $29 \pm 0.20^{g}$ & $0.003 *$ \\
\hline & $\mathrm{T}_{2}$ & $20 \pm 0.17^{\mathrm{a}}$ & $23 \pm 0.40^{b}$ & $26 \pm 0.180^{c}$ & $29 \pm 0.20^{d}$ & $29 \pm 0.20^{d}$ & $31 \pm 0.150^{f}$ & $32.05 \pm 0.1^{\mathrm{g}}$ & $0.001 *$ \\
\hline \multirow{2}{*}{$\mathrm{D}$} & $\mathrm{T}_{1}$ & $18 \pm 0.21^{\mathrm{a}}$ & $21 \pm 0.10^{b}$ & $23 \pm 0.40^{c}$ & $25 \pm 0.10^{d}$ & $26 \pm 0.180^{\mathrm{e}}$ & $27 \pm 0.230^{f}$ & $28 \pm 0.320^{g}$ & $0.003 *$ \\
\hline & $\mathrm{T}_{2}$ & $21 \pm 0.09^{\mathrm{a}}$ & $24 \pm 0.220^{b}$ & $27 \pm 0.270^{\mathrm{c}}$ & $30 \pm 0.440^{d}$ & $31 \pm 0.350^{\mathrm{e}}$ & $32 \pm 0.250^{f}$ & $34 \pm 0.10^{g}$ & $0.002 *$ \\
\hline
\end{tabular}

All values are means of triplicate determinations \pm standard deviation (SD), $\mathrm{T}_{1}$ - Hot Air Oven Drying, $\mathrm{T}_{2}$ - Freeze Drying Sample A-Mentha piperita, Sample B-Zingiber officinale, Sample C-Daucus carota and Sample D-Beta vulgaris filtrate impregnated coconut based snack, Rows followed by different alphabets are * Significantly different ( $\mathrm{p} \leq 0.05)$, NS- Not Significant by LSD.

\section{CONCLUSION}

Generally, consumer fondness on food products especially snack foods depends upon sensory attributes like color, flavour, texture etc., In the present study, the osmotically dehydrated coconut based snack further dried under hot air oven and freeze drying and then packed in Aluminium foil laminated LDPE pouches with infusion of $100 \%$ Nitrogen gas. The products were analysed for storage study range of 90 days and the impact was interpreted statistically using ' $t$ ' test at $(p \leq 0.05)$. . The use of Aluminium foil laminated LDPE pouches had influence on preservation of sensory traits and the adoption of MAP technology had contributed microbial inhibition on the storage quality of the product.

\section{ACKNOWLEDGEMENTS}

The authors show gratefulness to the Department of Food Science and Technology, Pondicherry University for having rendered laboratory facilities and UGC, New Delhi for the financial support through the award of Junior Research Fellowship.

\section{REFERENCES}

[1]. Lathika, M., \& Kumar, C. A. (2005). Growth trends in area, production and productivity of coconut in India. Indian Journal of Agricultural Economics, 60(4).

[2]. Madrau, M. A., Piscopo, A., Sanguinetti, A. M., Del Caro, A., Poiana, M., Romeo, F. V., \& Piga, A. Effect of drying temperature on polyphenolic content and antioxidant activity of apricots. European Food Research and Technology, (2009), 228(3): 441-448.

[3]. Torreggiani, D. Osmotic dehydration in fruit and vegetable processing. Food Research International, (1993), 26(1): 59-68.

[4]. Alzamora, S. M., Salvatori, D., Tapia, M. S., López-Malo, A., Welti-Chanes, J., \& Fito, P. Novel functional foods from vegetable matrices impregnated with biologically active compounds. Journal of Food Engineering, (2005). 67(1): 205-214.

[5]. Fito, P., Chiralt, A., Betoret, N., Gras, M., Cháfer, M., Martınez-Monzó, J., \& Vidal, D. Vacuum impregnation and osmotic dehydration in matrix engineering: Application in functional fresh food development. Journal of Food Engineering, (2001), 49(2): 175-183.

[6]. Nicoletti, J. F., Telis-Romero, J., \& Telis, V. R. N. Air-drying of fresh and osmotically pre-treated pineapple slices: Fixed air temperature versus fixed slice temperature drying kinetics. Drying Technology, (2001),19(9), 2175-2191.

[7]. Nieto, A., Salvatori, D., Castro, M. A., \& Alzamora, S. M. (1998). Air drying behaviour of apples as affected by blanching and glucose impregnation. Journal of Food Engineering, 36(1): 63-79.

[8]. AOAC., Official Method of Analysis of the Official Analytical Chemist (25th Ed.). Virgin. (1990).

[9]. Meilgaard, M., Civile, G.V., and Carr, B.T. Sensory evaluation techniques, (2nd) Edition, 1991, 354.

[10]. Stone, H., \& Sidel, J. L. (2004). Sensory evaluation practices. Academic press.

[11]. Rahman, M. S., \& Lamb, J. (1990). Osmotic dehydration of pineapple. Journal of Food Science and Technology, 27(3): 150-152.

[12]. Ranganna S. (2000). Vitamins In Hand book of Analysis and Quality Control for Fruit and Vegetable Products. (2nd) edition. Tata McGraw Hill publishing Co.ltd, New Delhi, 113-117.

[13]. Harnkarnsujarit, N., \& Charoenrein, S. (2011). Effect of water activity on sugar crystallization and $\beta$-carotene stability of freeze-dried mango powder. Journal of Food Engineering, 105(4): 592-598.

[14]. Negi, P. S., \& Roy, S. K. (2001). Effect of drying conditions on quality of green leaves during long term storage. Food research international, 34(4): 283287.

[15]. Dahiya, S., \& Dhawan, S. S. (2003). Effect of drying methods on nutritional composition of dehydrated aonla fruit (Emblica officinalis Garten) during storage. Plant Foods for Human Nutrition, 58(3): 1-9.

[16]. Lee, S. K., \& Kader, A. A. (2000). Preharvest and postharvest factors influencing vitamin C content of horticultural crops. Postharvest biology and technology, 20(3): 207-220.

[17]. Chang, C. H., Lin, H. Y., Chang, C. Y., \& Liu, Y. C. (2006). Comparisons on the antioxidant properties of fresh, freeze-dried and hot-air-dried tomatoes. Journal of Food Engineering, 77(3): 478-485.

[18]. Choe, E., \& Min, D. B. (2007). Chemistry of deep-fat frying oils. Journal of food science, 72(5): R77-R86.

[19]. Koczon, P., Gruczynska, E., \& Kowalski, B. (2008). Changes in the acid value of butter during storage at different temperatures as assessed by Standard Methods or by FT-IR spectroscopy. American Journal of Food Technology, 3(3): 154-163.

[20]. Abascal, K., Ganora, L., \& Yarnell, E. (2005). The effect of freeze-drying and its implications for botanical medicine: A Review. Phytotherapy Research, 19(8): 655-660.

[21]. Boran, G., Karaçam, H., \& Boran, M. (2006). Changes in the quality of fish oils due to storage temperature and time. Food chemistry, 98(4): 693-698. 